\title{
COMMODIFICATION OF CARE WORK IN THE INFORMAL SECTOR IN TURKEY: ROLE OF MEDIATING AGENCIES
}

\author{
Idil Safiye Soyseçkin Ceylan*
}

\begin{abstract}
The article analyzes role of mediating agencies in paid child care sector in informal labor market in Turkey. The main focus is meaning of commodification of child care in the condition of lack of any formal organization and monitoring. As a result of it is to be child care and to be performed in private sphere, complete penetration of market rules into working relation among child minders, mothers and mediating agencies are impossible. Therefore, child care as an informal employment moves between to be work and non-work.
\end{abstract}

INTRODUCTION

I. Mediating Agencies IN THE Feminist LiteratURE ...............................139

II. Role OF MEDIATING AGENCIES ........................................................... 141

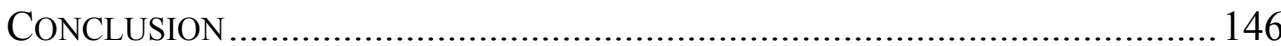

\section{INTRODUCTION $^{1}$}

Women perform care work in family as unpaid, since it is accepted as natural part of being woman. However, there are other women in somebody else's house caring their dependents in return of money. They are paid care workers. They are significant supporters of some women working out of home and having no close female relatives to share the responsibility, but can afford to hire someone else.

We have already known that reasons behind middle class mothers' choice of hiring child minders from informal labor market are insufficiency of policies aiming reconciliation of work and domestic responsibilities, and gendered division of labor at home. O'Connor (1993:512) ${ }^{2}$ mentions that differentiation of welfare regimes from each other is about how much people are independent from "pressures of the labor market" and how many they can access to public services "as citizenship rights", all of which

\footnotetext{
* Dr., Research Assistant, Kastamonu University. Research Fields: Gender, Woman's Labor and Employment, Child Care Work.

${ }^{1}$ This article is summary of a part of unpublished Ph.D. dissertation called "Nature and Dynamics of Informal Paid Child Care in Turkey: Commodification due to Insufficient Welfare Policies", METU, 2014.

${ }^{2}$ O'Connor, J.S., Gender, Class and Citizenship in the Comparative Analysis of Welfare State Regimes: Theoretical and Methodological Issues, 44(3) THE BRITISH JOURNAL OF SOCIOLOGY 501-518 (1993).
} 
display "extent of de-commodification".

In Turkey, regarding all kind of social services, level of decommodification is low. Especially for children smaller than three years, institutionalized child care services are quite a little. Furthermore due to the fact that quality of these facilities calls into question, most of women "prefer" their children to be cared for at home. Therefore, primarily they have to rely on female members of their family. Yet in case, none of them are available, mothers have to look for help of child minders in informal labor market since paid domestic work is not a regulated area. Large number of less educated lower class women sell their labor as child minders to bettereducated middle class working women.

Care providers and service receivers find each other mostly through two ways: kinship/friendship network and mediating agencies. Focus of this study would be on mediating agencies regulating this informal area.

The article is consisted of three parts. In the first part, a short literature review takes place while the second part presents how mediating agencies function. And the last part includes concluding remarks.

Data used throughout this study belong to in-depth interviews conducted with 19 working middle class mothers, 19 local child minders and three mediating agency managers, in the capital city of Turkey, Ankara. For interview with agency managers, three different regions were preferred: Kızılay, Ümitköy and YüzüncüY1l.

\section{Mediating Agencies in the FEMinist Literature}

The literature focusing on the function of mediating agencies is mostly consisted of the studies analyzing experiences of immigrant workers. The agencies are divided into two: The ones matching people, and the ones employing the care worker, which are home-care organizations. The agencies in the first category regulate the sector, in addition to matching potential workers and employers. Claims about these agencies are various, ranging from announcement of inexistent positions, to misinformation about scope of the work, ignoring contract agreed in the beginning and to imposing new contact prepared by employer; despite laws for protecting immigrant workers (Fudge, 2011) ${ }^{3}$. Furthermore they may consolidate existing class and race/ethnic hierarchies. According to Uttal and Tuominen

\footnotetext{
${ }^{3}$ Fudge, J., Global Care Chains, Employment Agencies, and the Conundrum of Jurisdiction: Decent Work for Domestic Workers in Canada, 23 CANADIAN JOURNAL OF WOMEN AND LAW 235 -285 (2011).
} 
$(1999)^{4}$, they change nature of employer-employee relation, especially to the disadvantage of the workers, because of decreasing negotiation power of care workers. On the other hand, some authors such as Aronson and Neysmith $(1996)^{5}$ and Constable $(2002)^{6}$ claim that - in case of inexistence of defined contract - isolated structure of home might increase exploitation. Thus, they think the agencies prevent exploitation. Yet, here it is noteworthy to differentiate the ones only mediate from the ones employing workers full time. Home care agencies are the best for matching workers and care/service receivers since care at home is - different from institutional care-mostly invisible that rapport and trust between them is depended on the agency's interpretation of needs and worker's resources ${ }^{7}$. Thus, when an agency only mediates, risk of tension between the worker and the employer will increase because there is not much possibility for care provider and the agency to know each other well.

Literature on immigrant domestic workers highlights that agencies also reinforce existing racial hierarchies ${ }^{8}$. As Constable displays working contracts do not always function for the sake of workers. In her research on Filipina workers in Hong Kong, what she found is that mediating agencies persuade employers to prepare and give to-dos and not-to-dos list. This list contains rules varying from working schedule to spare time activities, to what to wear, when to sleep, length of hair, make-up, and/or using perfume. To the author, these kinds of lists ensure "the worker's inferior position". On the other hand the same agencies give advice the workers to be obedient and polite, to smile all the time, to be ready every call of employers, and never raise their voices, etc.

Another example to sustentation of this hierarchy is Pratt's ${ }^{9}$ study in Canada on nanny agencies. She mentions the Live-in Caregiver Program developed by Canadian government to manage need of care workers. As she

\footnotetext{
${ }^{4}$ Uttal L. \&Tuominen, M., Tenuous Relationships: Exploitation, Emotion, and Racial Ethnic Significance in Paid Child Care-work, 13(6) GENDER AND SOCIETY 758-780 (1999).

${ }_{5}^{5}$ Aronson, J. and Neysmith S. M., You are Not Just in There to Do the Work: Depersonalizing Policies and Exploitation of Home Care-worker's Labor, 10 (1) GENDER AND SOCIETY 59-77 (1996).

${ }^{6}$ Constable, N., Filipina Workers in Hong Kong Homes: Household Rules and Relations, GLOBAL WOMEN: NANNIES, MAIDS, AND SEX WORKERS IN THE NeW ECONOMY 115-141 (B. Ehrenreich, A. R. Hochschild eds., New York, Henry Holt and Company Publishers 2002).

${ }^{7}$ Schmid, H., \& Hasenfeld, Y., Organizational Dilemmas in the Provision of Home-Care Services, THE Social SERVICE REVIEW 40-54 (1993).

${ }^{8}$ Anderson, B., Just Another Job? The Commodification of Domestic Labor, GLOBAL Women: NANNIES, MAids, AND SeX Workers In THE New ECONOMY 104-114 (B. Ehrenreich, A. R. Hochschild eds., New York, Henry Holt and Company Publishers 2002).

${ }^{9}$ Pratt, G., Stereotypes and Ambivalence: The Construction of Domestic Workers in Vancouver, British Columbia, 4(2) Gender, Place \& Culture: A Journal of Feminist Geography 159-178
} (1997). 
suggests, the program relies on perception that Canadians do not give this service. Also she underlines hierarchy established between European and Asian workers, which "European nannies are constructed as professionals; Filipinas as servants", "loving, patient and gentle" but having no capacity of thinking independently. These prejudices reflect on working agreements framing scope of the job and wage that Filipinas are expected to work more but earn less compared with Europeans.

As all researches display the agencies make both positive and negative effect on care work. From the positive side in case of inexistence formal regulating mechanisms, they become an address that both the employers and employees apply when some problems occur. Yet, since they are mostly established for profit-making, employers - as clients are "guarded and keep" more than the workers. Furthermore, as above studies display, mediating agencies strengthen present stratification regarding gender and race/ethnicity in society.

\section{Role OF Mediating AgEnCIES}

Legal mediating agencies or, with its common use, consultancy firms, in Turkey, have private employment agency status and work under the responsibility of the Turkish Employment Agency (ISKUR). They provide workers for cleaning, child care, and care for elder/unable people, and match intending employers and employees. Differences of these firms from acquaintance network are possibility of alternatives, presence of a written contract and supervising ${ }^{10}$.

Finding an appropriate person to work with is not easy. Mothers benefit from their social networks and from mediating agencies almost on equal basis. As it is clear, in case of little institutionalization, women have to rely on their own sources. Although mediating agencies provide some regulation informally, there is no formal organization and monitoring of the sector. This deficiency affects both mothers and child minders.

General tendency of mothers is sending word to acquaintances and applying the firms at the same time, which increase number of alternatives. This is a trend particularly while finding child minders for the first time. In case of needing a worker again, mainly the agencies are preferred. Furthermore, mothers employing child minders through the firms, mention

\footnotetext{
${ }^{10}$ However, it should be emphasized that they only mediates and do not force employers to provide a social insurance for the workers. In the contract, presence of an article stating necessity of social insurance mostly remains as a matter of form. Therefore while speaking of working conditions, it should be recalled that private employment agencies promote informal employment.
} 
that they find them more reliable since they hold many documents belong to care workers referring their places of living, health conditions, references, etc., which are explained in detail below. Moreover, a contract is another element making the agencies reputable in the eyes of mothers. Presence of an agency might be considered as a kind of assurance, because of existence of a written contract and of a place to be applied in case any kind of problem is faced up. Kaşka (2006) ${ }^{11}$, as well, brings forth agencies' function of producing solutions in case problems experienced between domestic workers and employers ${ }^{12}$.

Furthermore, for child minders, as well, finding a suitable family is a distressed condition. For many of them, the most common way of finding job seems to be their networks. Circle of acquaintances-varying from relatives to friends and neighbors - is a significant source for care work jobs. Many of these acquaintances had/have worked as child minder. This is a significant detail because before knowing someone else working in this job, many women told that they and, especially, their husbands, had been timid about place of the work, a house. Yet, as soon as they realized child minding has been performed widespread and women-who are considered low skilled - find chance to earn some money and "contribute" to family budget; their opinion has changed to positive. By time goes, depending on their working condition, these women have started to form a good example and source of reference for other women.

There is not a strongly mentioned reason behind preference of finding the job through their network. For some of them, it is an accustomed way that they have never thought of applying to an agency. For others, acquaintances appear to be more reliable compared with these firms. Bad reputation of the agencies - stigmatized as places covering prostitution, particularly, because of migrant women - underlies this idea.

Bringing two people together in a house is difficult, since they come from different economic, social and cultural backgrounds as Gülay, owner of an agency in Kizılay, points, "It is hard to get people of education and the ones having low level of culture together" summarizes how the agencies

\footnotetext{
${ }^{11}$ Kaşka, S., The New International Migration and Migrant Women in Turkey: The Case of Moldovan Domestic Workers, unpublished master thesis (İstanbul, Koç University 2006).

${ }^{12}$ Opening a parenthesis here is necessary that mediating agencies play different role for migrant domestic workers. As Atatimur's (2008) study demonstrates these institutions not only bring the workers and employers together, but also enable them to meet their migrant friends, and communicate with their families. In other words they offer socialization and communication opportunity for migrant workers. Atatimur, N., Reasons and Consequences of International Labor Migration of Women into Turkey: Ankara Case, unpublished master thesis (Ankara, Turkey, Middle East Technical University 2008).
} 
reflect on the sector and the workers. There are different methods used for achieving this mission, but, without doubt, experience very much matters.

While a woman to work as a child minder comes to a firm, there is a pre-selection phase, which is a combination of asking certain questions and relying on agency managers' judge of a character. In this sense Leyla, from YüzüncüY1l, very much relies on her 12 years' accumulation.

Of course I asked the known questions. She was really competent technically. She was also experienced, had references, but something was missing. Recognizing is relevant to my experience. I mean the 12-year of experience showed me that the lady sitting down in front of me had a serious problem and I should be careful about her.

According to mediating agency managers, the author spoke to, while deciding to whom to work with, they evaluate as if they look for a child minder. They say they do not take every application. There are many criteria they consider varying from personal care to family structure, to affection felt for children. Account of the owner of an agency in Kizılay, Gülay, makes clear that managers position themselves firstly as mother, which is considered as an essential condition in the sector. Before all else, they assess applicants according to their preference as if they look for a child minder.

Since I am a mother, I evaluate the workers as I employ them in my home. In case they suit my criteria, in case I say yes that I can have them as helping hand owing to the fact that my children are very young then it means that person is good for me. Criteria we have here vary from how she looks to her behaviors; how she speaks to how she dress and how clean she is, all of which are details for us. When she has a seat in front of us, we look over her. From nail care to cleanness of her hair, her body. If she smells or not, cleanness of her dresses, all of which are signs of cleanness of body and are very important. Besides, a person shows herself with her lady-like behaviors. We evaluate all these in the first instance.

Emphasis on cleanness of a child minder shows that agency managers' choices are coherent with what mothers look for. In addition to physical appearance, a proper Turkish accent is a significant criterion for employers. Leyla also refers to the same things: looking presentable and having a good elocution. She added that she referred the ones having a way of speaking that too much accentual to cleaning work. Here, child minders not to come into conflict with middle class values become apparent. They are considered as representatives of the employer's life styles.

Gülay, as well, emphasizes way the workers speak, and she connects this canon with self-development. Although she refers education as a criterion she mentions that they, as the agency, do not consider women who 
were "too slummier". Slummier here is used to signify social status of women, and to underline contrast between workers' and families' life styles. On the other hand, way of dressing is also important that application of women wearing "skimpy clothes" is not taken into consideration. "Families look for a worker who fits them, consequently."

It is the fact that child minders and cleaning workers are perceived and evaluated differently in the sector. The difference finds its reflection on cleanness, physical appearance, "ladylike" attitudes, and mode of pronunciation.

Furthermore, "bullheadedness" is a quality, which is not welcomed by the mediating agencies. "Being respectful and getting along with" mother are crucial. The firms do not want to work with employees, who are "dominant more than owner of the house". This is why Gülay advises the workers to "do whatever mother or father asks" child minders to do about children. She warns them not to "suggest anything wrong or right", because "this is the family's own decision."

Affection felt for a child is considered essential as the agency manager, Hale, in Ümitköy indicates, "I do not refer the ones coming for cleaning but then saying, 'at least I care for a child.' You cannot say, 'at least' if child is at stake." Although there is no formal standardization, some principles seem to be agreed on in the sector by all sides of working relation through circulation of information among social networks.

If a candidate passes the phase, her $\mathrm{CV}$ is required. Then a file is opened; and proof of residence, copy of identity card, record of conviction, health report and references are put in. Furthermore her preferences with respect to doing cleaning, age group she would like to work with, location of workplace, and if she likes presence of mothers and grandmother(s) in house are added in the file. References are called and their trueness is checked while also some information about the applicant is taken.

Usually a week is allowed for both of employers and employees to see if they could work together, which is called as a "time to live". If these seven days pass without problem, a contract is made that care worker, employer and the firm are the sides. In return of the service, employer should pay the firm an amount as a monthly wage of the worker, and if is not satisfied about the worker within three months, firm is obliged to send new candidates. This is a significant period because both mothers and child minders experience first month distressfully. After this one week, if everything is okay, contact is signed among mother, child minder and the agency.

In the contract, working days and hours, wage, amount and time of pay 
rise, day offs and responsibilities of employee are clearly specified. Duration of the contract, depending on firm, changes between three months to a year. Yet the expiration of it does not mean end of communication, as Hale underlines.

[...] As it is with families, I keep being a friend with the employees. That's what matters; the job does not mean everything. I do not have a rule like it is done. Of course I support them in every issue. I do whatever I can do to help them in every issue.

This is why, for instance, even after five years, a mother might call the firm and ask for advices about pay rise, and/or problem she experiences with her worker. Here an agency owner to associate job she does with family and friend relations indicates structure of the sector. As owners of the firms the author interviewed told her that it is very common to take a call in the middle of the night, or it is not unusual to put a care worker up in their home when she was beaten by her husband and cannot go back.

The firms refer many criteria about the workers, but not much about families. Yet, they mention a blacklist consisted of the ones who change workers ever so often within three months period of probation. Furthermore, families escaping payment in return of the service agencies offered and treating the workers badly are put into the list. Moreover, peace in family is considered significant owing to the fact that a stressful atmosphere will women to quit job in a very short time and cause the agencies to provide a new worker free of charge. In the sector, the agencies warn each other against these kinds of families. In other words, they establish a kind of a control mechanism. As it is clear, circulation of information is dense, fast and, has power of defining the boundaries of the field.

What Leyla confesses about men calling for care workers that the situation indicates how much the sector is female dominated and how traditional gender roles and motherhood are reproduced. She says, "A gentleman to call and tell me he would like to employ a child minder starts our relation from a negative point. And I ask, in an appropriate manner, where is your wife?" There are three reasons behind this attitude. One is "the sector to be opened to abuses" because working place is home, and secondly it reflects that man is the dominant in the family and on mother's life. This is worth to mention because these kinds of families tire the minders and cause them to leave the job, which means an extra burden for the agencies. Thirdly, care work is to be "grounded on motherhood, maternal instincts." According to Leyla, fathers cannot know everything about their child, which is related with their "nature".

Motherhood is also referred as a factor of distinction between local and 
immigrant domestic workers. As the managers the author met suggest that reason behind families to employ immigrant workers, called in the sector as foreigners, is because of the fact that local ones do not accept to work livein. Gülay remarks that she would rather have "Turkish women" because of finding them much more motherly. Her opinion rests on the fact that immigrant women do not have maternal feelings since they could leave their kids behind and manage to live without seeing them for three years, for instance. However, Turkish women cannot do, even their children are 25 years old, which is a sign of powerful motherly feelings.

Leyla, on the other hand, draws attention to their value judgment and morality. Despite she appreciates how they work in the week days, she mentions "darkness" of weekends. "There are the ones selling their body, or becoming blind drunk." Since reputation is important in the sector, she does not work with immigrant women.

Another point highlights traditional gender roles understanding is the managers' insistence on women as the best mediators in the sector. Agencies established by men are accused of considering this business as commerce, which is because of the fact that "men are not mothers." Gülay, though, admits that the work is commercial; she thinks it should be performed by the ones having "that feeling". "The sector", she says, needs "lady's mentality and opinions". Leyla, furthermore, concluded this widespread impression via emphasizing that both the employers and employees are women. This is why the female managers comprehend their requests and find solutions to their problems better than men can do.

\section{CONCLUSION}

Function of mediating agencies is only bringing potential workers and employers together, and then withdrawing. However, this does not mean they completely disappear in the relation. Despite the contract signed between workers, employers and the agencies are temporary, of which duration changes between three months to a year, an informal connection survives between them and families, and the workers.

Although the managers the author interviewed seem to stay a similar distance to both sides, they are closer to employee seekers. When they decide to which application to accept, they make an evaluation as if they look for a child minder. The managers locate themselves as mothers, above all. In accordance with middle class women, they attach importance to physical appearance of the workers varying from cleanness to way of dressing. In this sense, they judge cleaning workers and child minders 
differently, that this distinction is centered not only around physical appearance, but also ladylike' attitudes, and mode of pronunciation.

Contrary to criteria detailed about the employees, there is not a kind of list for families except the ones do not meet financial obligations of the contract. The agencies try to avoid the situations will cause them to frequently send new workers.

When the sector is taken into account as a whole, female domination becomes obvious. Despite the fact that finding a woman to support other women and providing employment for some other is liberating from one point, since it replicates traditional gender roles and isolate women in particular definitions centering on motherhood, it is restrictive.

All the accounts reveal that paid child care swings between to be a work and non-work. From the one side, it has a money relation, a written contract, boundaries and principles settled on, particular control mechanisms, wide human resources while on the other hand, it is considered as needing no skills other than being woman and having motherhood instinct. Child care, like other domestic works, is to be performed in house unpaid by female members of families make influence on this complication about the job. 